\title{
Discussion on the Influence of Public Psychology on Public Art
}

\author{
Wubin $\mathrm{Xu}$ \\ School of Art and Design \\ Wuhan University of Science and Technology \\ Wuhan, China 430081
}

\author{
Yuanfei Zhan* \\ School of Art and Design \\ Wuhan University of Science and Technology \\ Wuhan, China 430081 \\ *Corresponding Author
}

\author{
Chao Gao \\ School of Art and Design \\ Wuhan University of Science and Technology \\ Wuhan, China 430081
}

\begin{abstract}
Nowadays, the public psychology plays a very important role in the value and development of art. To understand the psychological needs of the public is helpful to carry out the artistic creation. It also can grasp the public psychology of the masses. According to reading "the crowdthe study on the public psychology", the author realizes the psychological research of the public. It also further extends to the development of contemporary public art. And it has made studies on the influence of public psychology on public art through exemplification, enumeration and other methods.
\end{abstract}

Keywords—public art; public psychology; integration of art and psychological; service groups

\section{INTRODUCTION}

Nowadays, the ideas are getting more and more open. Everyone has different views of the same thing. However, to understand the psychology of the public and to create better works of art become a difficult problem today. "The Crowd-A Study of the Popular Mind" is one of Gustave Le Bon's famous works. It explores the thought and behavior of the people in depth, and puts forward the ways to guide the psychology of the groups. In his book, he doesn't describe the group of random people. The thoughts and feelings of the group are all in one direction. To seize the psychological of the groups can be more conducive to the creation of art. And the creation wouldn't be groundless. It would have the support of things and thoughts.

\section{The PUBLIC PsychOLOGY}

Le Bon believes that two basic factors lead the transformation from traditional society to modern society. And the main reason of the transformation is the two factors. Namely, the destruction of traditional religions, political and social beliefs, and the technological development has brought huge changes for industrial production. He made a conclusion in his book. The construction of the future society needn't to care the belief and the opinions. However, the construction of the future society must take into account of new and supreme power. It is "the power of the group". "The age of the group" is shown in the change of ideas. The most prominent feature is the popularity of democracy and the concept of socialism. The characteristics of the group are affected by many aspects. First of all, people can feel an irresistible force from the number of groups. It is a group. The individuals needn't to bear the responsibility. The constraints will disappear for the individuals. Secondly, it is contagious. The people in this group would infect each other in ideas, psychology and behavior. Therefore, it would form the group psychology. Finally, the people of this group could be easily hypnotized. And the people of this group would imply and hypnotize each other. Then, the group psychology would be more serious and powerful.

The group is easily to make impulse. It is the group. The individuals needn't to have responsibilities. All of the things of the groups become so unpredictable. The sudden changes, impulses and rage are very terrible. The emotion of the group is exaggerated and simple, paranoid and conservative. The persons of the groups are infected with each other. They also rely on each other. So, their ideas become unified. It isn't just personal emotion. It is the emotion of the whole group. Any group will have a leader. Le Bon stresses the role of leaders. He argues that the construction of the belief could ignore religion, the politics and the society. In his opinion, it could ignore that the object of the belief is a book, a person or an idea. The establishment of belief is always depended on the role of the great leader of the crowd. The leader is necessary. They can act as the leader of the group. And the leader must be brave. The leaders should have appeal and lofty prestige. And the group must obey the leader. It is an instinct.

\section{THE PUBLIC ART}

As a new kind of art, it isn't popular with the public in the beginning. This is also the process of development of things. The public art has covered wide ranges. In any case, it would 
get much controversy at the beginning of new art. Brancusi is a Romanian sculptor. He created a sculpture named "Bird in space". And this sculpture is collected by Edward. Edward is an art collector. However, this sculpture is completed in Paris. So, this sculpture needs to be transported from Paris to New York. And this sculpture is bronze. The bronze is polished shiny and smooth. When the sculpture arrived in New York, the US Customs refused it to enter the United States. However, the United States has issued tax law. When the art work entered into the United States, the United States doesn't charge any tax. However, the US Customs believed that this sculpture wasn't a work of art, and it was only a piece of copper at that time. The public had paid attention to this event in the United States at that time. Brancusi finally decided to prosecute the US Customs. The lawsuit caused widespread concern in art world of New York. In the end, Brancusi won the case. In the case, Brancusi put forward what the art works are. The doubt is not only on sculpture. The decorative works of public art have also caused some doubts. Serra is a sculptor of the United States. He created the public art named "slant arch" in New York square. The theme of the works is on the steel wall. It is large decorative arts with curved shapes. At that time, the works caused the criticism of the people of New York. They thought that this works had taken the places. The people can't use the square. The works had taken up their recreational places. For Serra, the purpose of his works is to change the original understanding of the original space, and to break the usage mode of square in people's hearts. And in the end, the court determined to remove this works away. From these two examples, it can be seen that the public psychology and their understanding of the art works would have great impact on the art works. Of course, different art works have different evaluation in different times and environments. However, the art works should be adapted to the public. And it can provide an artistic enjoyment for the broad masses of the people.

\section{The Public Psychology AND Public ART}

In the era of big data and cloud computing and rapid development of information, the thought of the public is becoming more and more open. The psychology of the masses can directly affect the judgment of things. For example, the evaluation of new software determines its application. People's evaluation of the TV series determines its viewing quality and downloads. People's evaluation of literary and artistic works determines reading quality and so on. The public psychology and expectations would bring some new inspiration for the future creation. Firstly, it should choose the right crowd. Different groups have different ideas and characteristics. It should make creation according to unique ideas and characteristics of the group. The main body of the creation comes from the group and the real life. And then, the crowd would feel that the art is worth appreciating. Secondly, it should communicate with the leaders of the group to obtain more creation sources. In the creation, the role of leaders is essential, and people have group psychology. So, a good leader could take the lead to enjoy the works of art. It would be able to guide the masses to better feel the art. The group is unconscious, and it needs a leader. It should learn to control the emotions of the masses.
And it should grasp the dynamics of ideas. Then, artistic creation and their lives are inseparable. The difference between public art and other designs is that it needs to be evaluated by the public. The public art is placed in the public's vision. It can decorate, influence or change the life of the public. The public preferences and public psychology are very important for the creation of public art. The most important psychological of the masses is the group psychology. The designers should master the group psychology of the public. To use the psychological is important for the design of good public works of art. The designers should consider many aspects. For example, the popularity of the public like which kind of color and prefer to like which kind of shape. The public would select how much volume of art to put in the public space and so on. At the same time, it is important to make the masses have same feelings. There are some of the humanities in the public space, such as the history of each city, the Revolution of 1911, the Huangma uprising of Hong'an, the characteristics of each minority, the eaves of the Bai nationality, the cow head of the Va nationality, and so on. The humanity culture can be applied to the creation. The local people would resonate in these events.

Not only that, the public art design is on interaction. Therefore, the psychology of the masses is more important. Nowadays, many people can't understand contemporary art, and they even don't know what this works of art want to express. So it needs to go deep into the masses. With the extensive publicity, people would realize that they can feel public art everywhere. The public art can improve people's quality of life and bring more enjoyment. And then, people love public works of art. Also, it can develop and innovate the public art.

\section{CONCLUSION}

In this paper, it has described the public psychology. And it also has put forward the power of the group in the creation of the public art. It has strongly proved that artistic creation is inseparable from the people. The role of the public art in the society and art is important. The art works are closer to life and the masses. And the art works can improve people's quality of life, and enrich people's material and cultural life. At the same time, it also discusses the scientific connotation of the relationship between public psychology and public art. And it believes that to deal with the relationship between the public psychology and the public art is helpful to create more good works. And it can meet the requirements of the broad masses of the people.

\section{REFERENCES}

[1] Chang Yuxing. Analysis on the psychology of network name in modern media environment [J]. News world, 2011, (7): 215-216.

[2] Cai Chuhong. Microblogging mobs [J]. Emerging Media, 2011, (8) 99-100.

[3] Liu Jialei. Analysis on the psychological thinking of Le Bon group [J]. Creative Economics Theories, 2013, (35): 70-71. 
[4] Zhu Qin. A brief analysis of group psychology — A study of Le Bon 's theory of group psychology [J]. Enterprise Guidance, 2010, (1): 273274.

[5] Sun Qinhao. The group psychology in the revolutionary ageReading Gustav Le Pen 's "The Crowd" [J]. Theoretical Observation, 2011, (2): 36-37.

[6] [France] Gustav Le Bon. The Crowd-The Study of Group Psychology [M]. Beijing: Central Editorial Publishing House, 2005.

[7] Wang Zhong. Introduction to Public Art (Second Edition) [M]. Beijing: Peking University Press, 2014.

[8] Liu Yinyin. Public art and mode: the East and the West [M]. Shanghai: Shanghai Science and Technology Press, 2008.

[9] Li Jiansheng. Public Art and Urban Culture [M]. Beijing: Peking University Press, 2012.

[10] Huang Jianmin. Public art in life [M]. Jilin: Jilin Science and Technology Press, 2002. 